Símbolos de riqueza e modernidade:

Teatros no Pará, Rio de Janeiro e São Paulo

\title{
SÍMBOLOS DE RIQUEZA E MODERNIDADE: TEATROS NO PARÁ, RIO DE JANEIRO E SÃO PAULO ${ }^{1}$
}

\author{
SYMBOLS OF WEALTH AND MODERNITY: \\ THEATERS IN PARÁ, RIO DE JANEIRO AND SÃO PAULO
}

\author{
SÍMBOLOS DE RIQUEZA Y MODERNIDAD: \\ TEATROS EN PARÁ, RÍO DE JANEIRO Y SÃO PAULO
}

Luís Pedro Dragão Jerônimo

\begin{abstract}
Resumo
O edifício teatral servia não apenas enquanto local de entretenimento, mas também como importante símbolo do sucesso econômico e do prestígio das suas cidades. Neste artigo, analisamos aspectos materiais $e$ simbólicos de edifícios teatrais no Pará, Rio de Janeiro e São Paulo, escolhidos por serem de cidades em grande expansão econômica nos períodos de construção de seus principais palcos. Visamos estabelecer pontos de contato entre essas construções e apresentá-las como constituintes de um mosaico de outros edifícios que evocavam ideais cosmopolitas e modernos, que marcaram as paisagens urbanas dessas localidades entre o fim do século XIX e o início do século XX.
\end{abstract}

Palavras-Chave: Teatros - Primeira República Brasileira - Pará - Rio de Janeiro - São Paulo.

\begin{abstract}
The theater building served not only as a place of entertainment, but also as an important symbol of the economic success and prestige of its cities. In this article, we analyze material and symbolic aspects of theatrical buildings in Pará, Rio de Janeiro and São Paulo, chosen because they are cities with great economic expansion during the construction periods of their main stages. We aim to establish points of contact between these constructions and present them as constituents of a mosaic of other buildings that evoked cosmopolitan and modern ideals, which marked the urban landscapes of these locations between the end of the 19th century and the beginning of the 20th century.
\end{abstract}

Keywords: Theaters - First Brazilian Republic - Pará - Rio de Janeiro - São Paulo.

\section{Resumen}

El edificio del teatro sirvió no solo como un lugar de entretenimiento, sino también como un símbolo importante del éxito económico y el prestigio de sus ciudades. En este artículo, analizamos aspectos materiales y simbólicos de edificios teatrales en Pará, Río de Janeiro y São Paulo, elegidos porque son ciudades con gran expansión económica durante los periodos de construcción de sus escenarios principales. Nuestro objetivo es establecer puntos de contacto entre estas construcciones y presentarlas como componentes de un mosaico de otros edificios que evocaron ideales cosmopolitas y modernos, que marcaron los paisajes urbanos de estos lugares entre finales del siglo XIX y principios del siglo XX.

Palabras Clave: Teatros - Primera República Brasileña - Pará - Rio de Janeiro - São Paulo.

\footnotetext{
${ }^{1} \mathrm{O}$ presente artigo deriva de uma pesquisa mais ampla, intitulada "Uma memória e um espaço restaurado em dois tempos: O Theatro Municipal de São João da Boa Vista no momento de sua construção (1914) e a partir de seu restauro, dos anos 1980 aos dias atuais", desenvolvida junto ao Programa de Pós-Graduação em História Social da Universidade de São Paulo, com apoio financeiro do Conselho Nacional de Desenvolvimento Científico e Tecnológico (CNPq).

${ }^{2}$ Bacharel e Licenciado em História pela Universidade de São Paulo - USP. Mestre em História Social pela Universidade de São Paulo - USP. E-mail: luispedrodj@ hotmail.com
} 


\title{
Símbolos de riqueza e modernidade: Teatros no Pará, Rio de Janeiro e São Paulo
}

\section{INTRODUÇÃO}

\begin{abstract}
"afetada por esse surto de progresso, suas condições sociais passaram a indicar a necessidade de ser ela dotada de uma casa de espetáculos em condições de receber, condignamente, as companhias teatrais que aí chegavam (...)" (AMARAL, 2006, p.579)
\end{abstract}

O trecho acima, retirado da monumental obra História dos Velhos Teatros de São Paulo (de 1979), em suas linhas gerais, de nenhuma forma se restringe apenas à cidade de São Paulo. Suas palavras podem ser usadas, em parte, para explicar a construção de edifícios teatrais de grandes dimensões em várias cidades brasileiras, desde Belém do Pará e Santos, ainda no século XIX até Campinas e Ribeirão Preto dos anos de 1930, passando pela Capital Federal, Jundiaí e São João da Boa Vista dos anos de 1900 e 1910.

Muito embora as motivações para o crescimento das cidades aqui listadas tenham sido diversas (no caso carioca, motivada pela riqueza gerada pela centralidade política, e nos vastos recursos dos quais dispunham os cofres da Capital Federal de então; no caso belenense, pelo ciclo da borracha; e no caso paulistano, campineiro, ribeirão-pretano, jundiaiense, santista e sanjoanense, pelo café), todas elas têm em comum um exemplar de teatro de grande porte, erguido ou projetado no contexto de suas expansões econômicas, simbolizando seus poderes locais e regionais. Estes teatros, combinados com a remodelação de praças, com a construção de edifícios públicos (e particulares) de elaboradas fachadas e inovadoras técnicas, com a abertura de novas vias e com a implementação de um conjunto de valores e de uma "civilidade" tanto imposta quanto buscada, se configuram elementos verdadeiramente necessários à “indumentária” urbana. Mesmo que em contextos diferentes, seus significados são os mesmos: símbolos de modernidade, riqueza, poder e civilização. Assim, podemos considerar que o teatro

é um fenômeno eminentemente urbano. A origem, o desenvolvimento, as transformações, o ligam inerentemente às atividades urbanas, citadinas. É um programa construtivo típico de cidades. $\mathrm{O}$ aparecimento do edifício para teatro em determinado local está vinculado a sua expansão econômica, populacional e física, quando adquire o status de cidade, ou seja, quando rompe com os vínculos mais estreitos com o campo, não dependendo mais diretamente de uma produção de subsistência e proclamando-se autossuficiente, congregando serviços religiosos, administrativos, adquirindo força política, consolidando um sistema de produção e distribuição de bens, proporcionando cultura, lazer, recreação, isto é, uma vida urbana" (MASSERAN, 2012, p.181, grifo nosso)

A fim de facilitar o percurso sobre as relações entre os teatros aqui tratados, os dividimos em dois grupos, de recortes temporais distintos, mas que se referem aos locais (capitais ou interior) em que estão inseridos: do primeiro grupo fazem parte o Theatro Da Paz, em Belém do Pará, inaugurado em $1878^{3}$, o Theatro

\footnotetext{
${ }^{3}$ Este teatro passa por duas reformas antes que seus congêneres do Rio de Janeiro, São Paulo, Campinas, Ribeirão Preto, Jundiaí e São João da Boa Vista aqui expostos fossem construídos, sendo a primeira entre os anos de 1887 e 1890 e a segunda, entre os anos de 1904 e 1905. Silveira (2010) aponta que o Teatro da Paz hoje é conhecido pelo aspecto material que ganhou após a reforma de 1904/1905, quando se "estabeleceu um outro marco de originalidade na história do teatro,
} 


\section{Símbolos de riqueza e modernidade: Teatros no Pará, Rio de Janeiro e São Paulo}

Municipal do Rio de Janeiro, inaugurado em 1909 e o Theatro Municipal de São Paulo, inaugurado em 1911; do segundo grupo fazem parte o Theatro Guarany de Santos, inaugurado em $1882^{4}$, Teatro Polytheama de Jundiaí ${ }^{5}$, inaugurado em 1911, o Theatro Municipal de São João da Boa Vista, inaugurado em 1914, o Teatro Municipal Carlos Gomes de Campinas, inaugurado em 1930 e o Teatro Pedro II de Ribeirão Preto, também inaugurado em 1930.

\section{AS DIFERENÇAS ENTRE AS CASAS DE ESPETÁCULOS: ALCANCE SIMBÓliCO, USOS E DISPOSIÇÃO NOS LOTES}

As diferenças entre os grupos se encontram, principalmente, no alcance simbólico de suas construções e na forma como estes espaços são utilizados pelos respectivos públicos. O primeiro grupo, não coincidentemente, se refere aos teatros de maior dimensão simbólica e que, localizados em capitais provinciais/estaduais, possuem um maior capital de representação dos anseios das altas burguesias que os construíram. Neste sentido, são representantes nacionais, com alcance internacional e possuindo um capital de representação de civilidade, poder e prosperidade mais abrangente que os teatros do interior. O segundo grupo de teatros também são de grandes proporções, de grande valor artístico e cultural, tanto quanto os do primeiro grupo, porém, enquanto os teatros do primeiro grupo tinham projeções nacionais, construídos como vitrines das burguesias provinciais/estaduais e até mesmo nacionais, os teatros do segundo grupo são menos abrangentes em área e mais circunscritos às regiões em que se encontram, demonstrando um poderio mais localizado e relacionado às cidades ou a uma região específica e, portanto, menos abrangente. Esta característica local, claramente, não desabona suas trajetórias, mas sim os torna ainda mais importantes nos contextos regionais respectivos, já que suas existências são relativamente raras e marcadas de um alto prestígio dessas construções nas regiões em que se encontravam.

Como não poderia deixar de ser, numa sociedade onde a hierarquia social era bem observada a partir de gostos, gestos, vestimentas e ideias, estes teatros de capitais se diferem dos outros por serem geralmente menos democráticos e com uma utilização, na maior parte das vezes, voltada a uma pequena faixa da população (a elite socioeconômica). Vemos, nos programas de apresentações, uma elitização de seu espaço, com predileção pelas óperas e pelos espetáculos de alto custo. Quando não utilizados para fins culturais, seus

sendo uma ação política de apagamento de sua história pretérita, associada à decadente Monarquia, com a reelaboração da imagem do teatro-monumento e a consequente afirmação do imaginário da República e dos elementos da modernidade instaurada em Belém" (SILVEIRA, 2010, p.24), modernidade esta que evoca o fausto da borracha e o luxo do ecletismo. Por este motivo, ao falarmos de dimensões, capacidade e usos, falamos de antes da reforma de 1904/1905, enquanto que seu estilo será tratado tendo como base o instituído após a referida reforma.

${ }^{4}$ Caso semelhante ao do Teatro da Paz é o do Guarany, de Santos, inaugurado em 1882 e que sofreu profundas reformas em 1910, quando recebeu ornamentações na fachada e um acréscimo onde funcionaria a bilheteria, sendo atualmente conhecido pelo aspecto criado após essa reforma.

${ }^{5}$ Inaugurado em 1911, era um simples pavilhão e, após uma reforma em 1927, adquiriu traços de teatro com palco italiano e sala em ferradura, aliado a um melhor acabamento e uma maior ornamentação interna e externa. 


\section{Símbolos de riqueza e modernidade: Teatros no Pará, Rio de Janeiro e São Paulo}

eventos se voltavam também ao público elitizado, servindo como local para banquetes, comícios e bailes de carnaval, como é o caso paulistano, o qual Macedo (2011) detalha, afirmando que

nem só de apresentações artísticas vivia o Municipal. Ali também realizavam-se festas beneficentes de todo o tipo, fosse em prol das vítimas das guerras, dos órfãos das revoluções, dos refugiados ou dos tuberculosos, além de banquetes, convenções partidárias e bailes. Seu significado simbólico não escapou aos líderes políticos, e por isso era o local preferido para reuniões, jantares de confraternização e outros eventos do Partido Republicano Paulista. Foi ainda no Theatro Municipal que o conde Ermelino Matarazzo, falecido em um raid automobilístico nos Alpes em 10 de fevereiro de 1937, recebeu exéquias e as últimas honras póstumas. As dezenas de formaturas constituem um capítulo à parte (...) os festejos carnavalescos também faziam parte do calendário anual do teatro (...) (MACEDO, 2011, p.55).

Macedo (2011) apresenta diversos usos das instalações do Municipal paulistano, mas não vemos registros de outras atrações que não fossem promovidas ou destinadas à elite, nem muito distante do seu perfil e gostos. Desta forma, mesmo que o Theatro Municipal de São Paulo tenha abrigado outros eventos sociais fora do âmbito artístico, não vemos uma maior popularização de seu espaço. Ele, apesar de festas e bailes, ainda era um reduto das elites, construído por elas e usufruído, em grande parte, por elas. Esta destinação, claro, não agrada aos "infelizes" que ficam de fora deste pequeno e seleto clube de frequentadores, e é o que Moraes (2013) retoma ao afirmar que

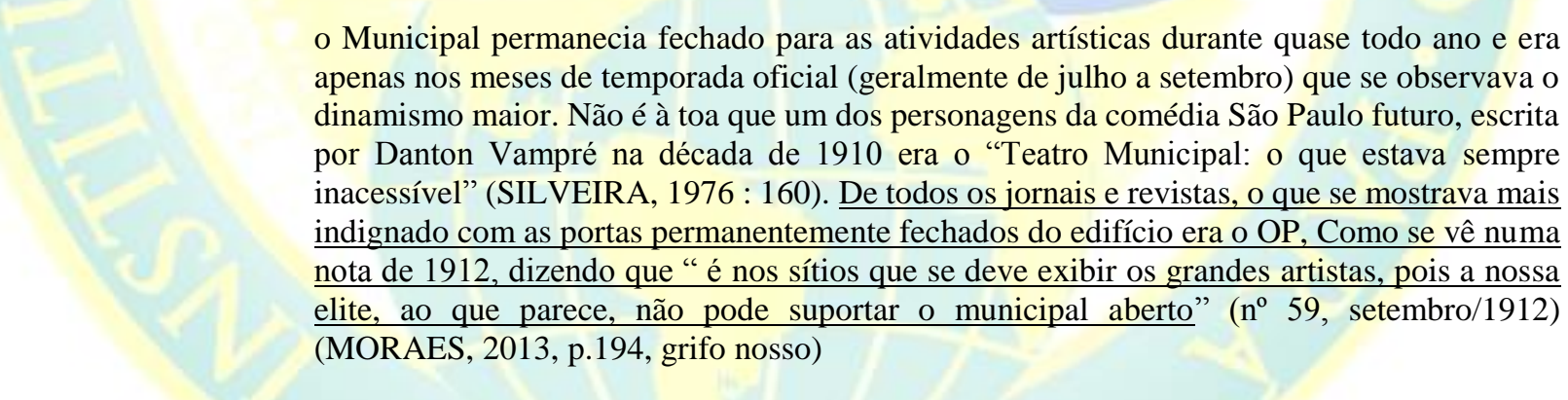

E continua, ao afirmar que

o cronista critica novamente as portas fechadas dos palcos às atrações, desta vez porque o edifício estaria sendo utilizado para outros fins, não ligados às artes: 'o Municipal, que custou os olhos da cara (...) está fechado. Isto é: fechado como teatro, porém aberto como casa de chá e outras "cositas más"” (nº 14, nov./1911, ver também idem, n²0, dez./1911) (...) (MORAES, 2013, p.195).

Estas “cositas más" são, provavelmente, as destinações anteriormente citadas e elencadas por Macedo (2011), ao passo que Moraes (2013) fornece importante justificativa sobre esta "deturpação" do uso da construção por atividades alheias à arte:

De fato, do ponto de vista econômico, parece bastante razoável que o teatro, na ausência de atrações ou demais atividades culturais, dedicasse-se à realização de festas e comícios, 


\section{Símbolos de riqueza e modernidade: Teatros no Pará, Rio de Janeiro e São Paulo}

mantendo sua geração de renda através do aluguel de seus salões aos clubes e associações. $\mathrm{O}$ problema, contudo, é que a utilização do local para atividades sem viés artístico, isto é, com caráter exclusivamente mundano, parece ter afetado também as noites de temporada (MORAES, 2013, p.196).

Essa dimensão financeira do caso paulistano, apontada pelo autor, relaciona-se muito bem com a realidade de outras casas de espetáculos (deste primeiro grupo ou do segundo grupo de teatros) e as suas diversas destinações, fora do âmbito artístico. Construídas como teatros, abrigavam também banquetes, comícios, exposições e outras formas de entretenimento tais como o cinema, espetáculos circenses etc. Este foi o lado forçoso da necessidade de lucro, para sua própria manutenção, que proporcionou a essas casas de espetáculos (que em muitos casos eram propriedades de empresas) usos tão amplos e, muitas vezes, desconexos de suas funções originais. Essa adaptação mostra o esforço daquelas casas de espetáculos em responder ao capital investido em suas construções, seja por acionistas particulares, seja pelos poderes públicos das cidades, sendo claro que foi a necessidade de viabilização quem definiu, em grande medida, os usos (mais ou menos conexos com os gostos e ideais de uma elite socioeconômica que pretende ser também cultural) daqueles destacados teatros.

Sobre o caso carioca, não vimos menções a outros usos que não aqueles voltados ao público de elite, ainda que ele tenha sido "usado ao longo dos anos para os mais variados fins, de bailes de carnaval a solenidades de formatura e uma infindável lista de cursos de balé ou declamação" (SANTOS, 2011, p.102). "Variados fins para um seleto grupo de usuários, portanto. Já no interessante caso belenense, vemos uma dinâmica de uso muito maior daquele espaço em relação aos seus outros dois congêneres, se assemelhando aos usos polivalentes dos espaços do segundo grupo, de teatros do interior (menores e de alcance regional), podendo mesmo considerar este teatro como uma intersecção entre os dois grupos. Se é verdade que partilha com os teatros paulistano e carioca um alcance simbólico nacional, e se se comporta como um modelo para outros menores, seus usos (pelo menos num período inicial) o colocam mais ligado ao segundo grupo de teatros, de menor escala simbólica, fazendo-o muito mais atento aos anseios de um público mais variado e com menor capital cultural que seus dois companheiros de grupo. Desta forma, não se trata de um teatro de todo excludente, mas, pelo contrário, com considerável participação popular em seu público, o que impactaria, inclusive, sua programação. Assim, o Teatro da Paz tem como característica de seus primeiros anos de funcionamento ${ }^{6}$ um uso polivalente, onde

além das encenações dramáticas e líricas, havia as atrações bizarras, como os números do magnetizador italiano Pedro D'Amico e seu filho Vicente: a “mui divertida dança magnética"; as experiências corporais com o aumento e desaparição da pulsação; insensibilidade parcial, atravessando o braço da pessoa magnetizadas com comprido alfinete (...) (SILVEIRA, 2010, p.133)

\footnotetext{
${ }^{6}$ As considerações sobre os teatros aqui tratados se referem, majoritariamente, aos seus primeiros anos de funcionamento. 


\section{Símbolos de riqueza e modernidade: Teatros no Pará, Rio de Janeiro e São Paulo}

Mesmo nas ocasiões em que havia atrações voltadas, principalmente, às elites, Silveira (2010) apresenta uma utilização por outros públicos menos favorecidos:

O teatro fora planejado e construído para, idealmente, atender à "classe mais ilustrada da população", mas na cidade real recebeu outros segmentos da sociedade, não apenas a elite. Há indícios da circulação de um público de origem mais modesta, que também tomava assento na sala de espetáculos. Um motivo plausível era o fato de o governo provincial subsidiar temporadas artísticas, permitindo aos empresários a oferta de ingressos a preços regulados aos dos teatros mais populares. Outro, a realização de récitas em benefício de causas sociais, as quais eram desoneraras do valor do aluguel, podendo, portanto, oferecer ingressos a preços toleráveis para população de baixa renda (SILVEIRA, 2010, p.140).

Essa assistência e programação mais democráticas são bem presentes no interior. É lá, onde existia a carência de público, empresários e espaços adequados para grandes apresentações, que os seus teatros apresentaram as mais variadas atrações e, vez ou outra, apresentações eruditas. Em Santos, no Guarany, vemos apresentações de companhias nacionais e internacionais nos seus primeiros anos de funcionamento e, já na década de 1920, o seu funcionamento enquanto cinema e teatro (PEREIRA, 2008, p.63). Em Jundiaí, no ainda "Pavilhão Polytheama", havia apresentações de peças teatrais populares, "circo de cavalinhos" e exibições de filmes, em tela adaptada, conforme aponta Martins et al. (1996, p.13).

Em São João da Boa Vista, no seu Theatro Municipal, vemos o uso do mesmo como local de apresentações de palco, em sua maioria populares, ocorrendo muito raramente apresentações eruditas e ainda assim com pequenos grupos de artistas, e do seu uso sobretudo como cinema, depois sendo também utilizado como local de bailes de carnaval, chás dançantes e festivais amadores. A inclinação popular também aparece nos vários depoimentos colhidos para o livro de Fardin (2000), que apresenta uma coletânea de memórias do Theatro Municipal Carlos Gomes, de Campinas, demolido em 1968, onde podemos perceber o uso variado do espaço, que abrigava desde exibições de filmes a peças teatrais, festivais amadores, bailes de formatura, e, raramente, grandes óperas e espetáculos líricos. Caso semelhante ocorre com o Theatro Pedro II, em Ribeirão Preto. Segundo Cicaccio (1996), "no passado, um teatro acolhia de tudo um pouco. Cinema, ópera, montagem teatral, música, balé, eventos cívicos, políticos e sociais, bailes... não fugiu à regra o Theatro Pedro II (...)" (CICCACIO, 1996, p.76) e, no que se refere à ocorrência de grandes espetáculos e óperas, aponta que

ópera de verdade, acompanhada de orquestra completa, com montagem cenográfica daquelas que se veem em grandes centros, em vídeo ou na televisão -, foi programa raro no Pedro II. "Bem mais raro", garante Guilherme Simões Gomes. O que houve mesmo foi muita "cortina lírica", com execução de trechos de ópera por cantores locais e de fora (CICCACIO, 1996, p.79)

Assim, vemos nas operações dos teatros do segundo grupo uma racionalidade econômica no que se refere aos seus usos. Nesse sentido, a opção mais viável economicamente seria a de diminuir o nível de erudição e requinte das atrações, aumentando seu aspecto de simples entretenimento, buscando sempre o equilíbrio das contas e o sucesso das respectivas empresas (algumas arrendatárias, outras administradoras). É 


\section{Símbolos de riqueza e modernidade: \\ Teatros no Pará, Rio de Janeiro e São Paulo}

importante ressaltar que a concepção de que os teatros são empreendimentos financeiros que deveriam gerar lucro também está presente nos teatros de capitais, como vimos, porém, a questão financeira é muito mais urgente no interior do que nas capitais, sendo ela de grande interesse para se analisar os espetáculos e variados usos destes teatros.

Por fim, em relação à materialidade das construções, podemos perceber que a disposição dos teatros em seus lotes também possui padrões diferentes nos teatros das capitais e nos teatros do interior, com apenas uma exceção (o Theatro Municipal Carlos Gomes foi construído no mesmo local que seu antecessor, o Theatro São Carlos, demolido no início dos anos de 1920, daí o lote isolado). Enquanto que os teatros paulistano, carioca e belenense são construídos em lotes isolados, os exemplos jundiaiense, ribeirão-pretano, santista e sanjoanense são construídos em lotes flanqueados por outras construções/terrenos. Nestes casos, há relativa perda da monumentalidade e destaque no horizonte da cidade, muito embora isso seja compensado pelas grandes dimensões dos edifícios em relação às construções vizinhas.

\section{AS SEMELHANÇAS ENTRE AS CASAS DE ESPETÁCULOS: LOCALIZAÇÃO, FORMATOS, ESTILOS E ELEVADOS CUSTOS DE CONSTRUÇÃO}

Se há poucas diferenças entre os dois grupos de teatros, as semelhanças já são mais numerosas e se referem à localização destes espaços no tecido urbano correspondente, ao formato de suas salas, aos materiais construtivos e aos estilos arquitetônicos adotados, com maior ou menor elaboração/acabamento, que se inserem num período em que se convencionou importar estilos e técnicas ao se construir edifícios europeizados, símbolos máximos da inserção das respectivas cidades na modernidade burguesa. Também buscaremos citar os custos das obras, quando estes estiverem disponíveis, e que configuram importante medidor para avaliarmos o compromisso firmado pelos poderes públicos e pelas sociedades anônimas em verem seus projetos de teatro concluídos.

Em todos os teatros aqui tratados, podemos perceber a proximidade e a inserção dos mesmos nos trajetos de sociabilidade compostos de praças, ruas e avenidas centrais de suas cidades, além da proximidade de alguns deles com construções que representavam os diferentes poderes (político, nas Câmaras; judicial, nos Fóruns; religioso, nas Matrizes) e que geralmente compartilhavam, com seus teatros, fachadas ecléticas que marcaram a paisagem urbana do período. Podemos afirmar, portanto, que os grupos de teatros guardam semelhanças entre si por sua localização privilegiada nos respectivos tecidos urbanos do período.

O Theatro Municipal do Rio de Janeiro é o paradigma nacional maior (para os teatros erguidos posteriormente) no que se refere à sua localização, uma vez que se situava no epicentro da vida cultural e social carioca, fluminense e, claro, brasileira. Construído antes ou depois de outros marcos em seu espaço, o Municipal carioca se conectava com a Avenida Central, a Rua Evaristo da Veiga, a Praça Floriano e, mais longínquo, com o Passeio Público. Sobressaia-se num conjunto de imponentes edifícios tais como o Clube 


\title{
Símbolos de riqueza e modernidade: Teatros no Pará, Rio de Janeiro e São Paulo
}

Naval, a Biblioteca Nacional, a Escola Nacional de Belas Artes, o Supremo Tribunal Federal, a Câmara dos Deputados (abrigada no Palácio Monroe até 1922), entre outros, que partilhavam de estilos semelhantes, mais precisamente os de inspiração parisiense. Sobre esta inspiração importada, Ermakoff (2010) aponta que

\begin{abstract}
a inauguração do Theatro Municipal do Rio de Janeiro, em 14 de julho de 1909, foi um marco na vida cultural da cidade, que passou a dispor de uma casa de espetáculos comparável, em beleza, tamanho e conforto, àquelas que se sobressaíam no mundo civilizado no alvorecer do século XX. Não por acaso, a solenidade se deu no mesmo dia da Queda da Bastilha, que marcou o início da Revolução Francesa. Orgulhosa, a cidade do Rio de Janeiro homenageava o país com o qual mantinha maior afinidade cultural. A ligação era tão forte, que os responsáveis pela construção do novo teatro se inspiraram na arquitetura da Ópera de Paris (Garnier), obra-prima inaugurada em 1875, cuja beleza encantou o mundo (ERMAKOFF, 2010, p.16, grifo nosso).
\end{abstract}

No caso de Belém do Pará, o Teatro da Paz situava-se na importante Praça Dom Pedro II, anteriormente conhecida como Largo da Pólvora e, atualmente, por Praça de República (SILVEIRA, 2010, p.39), local fortemente marcado pelo footing das elites belenenses. Segundo a autora, o local em que o Theatro da Paz estava situado era mais conhecido, no início do século XX e após as diversas reformas urbanísticas típicas do período, como a "Montmartre paraense (...) em alusão ao legendário bairro parisiense" (SILVEIRA, 2010, p.46). Já para o Theatro Municipal de São Paulo, sua localização é emblemática no tecido urbano paulistano. Segundo Brandão (1993),

em pouco tempo, a partir de sua inauguração, o Municipal se transformou em ponto de referência, visita obrigatória para estrangeiros, passeio turístico para os paulistanos em finais de semana. O teatro estabeleceu uma dualidade na região. Porque, naqueles anos, a São Paulo que contava, frequentava o lado oposto, o chamado Triângulo, espaço compreendido entre as ruas Direita, São Bento e XV de Novembro. Ali se fazia o footing, pessoas se encontravam, passeavam, frequentavam casas de chá e sorveterias, restaurantes, confeitarias (Paulicéia, Fasoli e Sportsman), cinemas, escritórios, grandes bancos e jornais (...) Tudo se concentrava no Triângulo, febril, agitado e refinado. Movimentadíssimo, principalmente entre as 16 e 18 horas. Suas vitrines, com o que havia de melhor na Europa, atraíam as mulheres. São Paulo enriquecia. Entre o Triângulo e o Municipal, o Viaduto do Chá, divisor de águas (BRANDÃO, 1993, p.27, grifo nosso).

É interessante notar que o Theatro Municipal de São Paulo serviu para "expandir" o trajeto de sociabilidade paulistano na época, ampliando-o para além do Viaduto do Chá, fora do tradicional limite triangular $^{7}$ do bom gosto e do requinte. Se nos casos anteriores e nos seguintes os teatros foram construídos em locais já consolidados no que se refere às áreas de sociabilidade das respectivas cidades, no caso paulistano foi o teatro quem amplamente contribuiu para a expansão dessa área, para o "outro lado" do Viaduto do Chá.

\footnotetext{
${ }^{7}$ Para uma melhor compreensão do refinado espaço triangular, ver: BARBUY, Heloisa. A Cidade-exposição - Comércio e Cosmopolitismo em São Paulo, 1860-1914. São Paulo: EDUSP, 2006, 304p.
} 


\section{Símbolos de riqueza e modernidade: Teatros no Pará, Rio de Janeiro e São Paulo}

No segundo grupo analisado, o caso mais claro da proximidade entre os teatros e os outros pontos de interesse social e de poder é o do Theatro Municipal de São João da Boa Vista. Ele estava situado muito próximo da Câmara Municipal, do Fórum e da Matriz (situado atrás do templo) e ainda integraria o trajeto de sociabilidade sanjoanense compreendido pelos clubes de imigrantes, pelo Clube Recreativo Sanjoanense e pelas Praças Joaquim José, Da Matriz e a Avenida Dona Gertrudes. Acompanhando-o está o Theatro Municipal Carlos Gomes, que ficava atrás da Matriz campineira e próximo das Avenidas Francisco Glicério e Campos Sales. Também em local central ficava o Polytheama, situado à Rua Barão de Jundiaí (antiga rua Direita), de grande notoriedade na cidade. No caso ribeirão-pretano, o Pedro II estava relativamente distante da Matriz ribeirão-pretana, mas inserido num espaço de sociabilidade fortemente pautado pelo entretenimento, situandose no "Quarteirão Paulista", nome que derivava da proprietária dos imóveis, a Cervejaria Paulista. Além de se situar neste Quarteirão, tinha a Praça XV de Novembro como sua vizinha de frente, separados pela Rua Álvares Cabral e, bem próxima a ele, encontram-se as Ruas São Sebastião, Duque de Caxias, General Osório e Amador Bueno, de grande circulação no centro da cidade. Por fim, no caso santista, o Guarany também estava situado em um local central na cidade daquele período, na Praça dos Andradas, e bastante próximo do Paço Municipal (Casa de Câmara e Cadeia), da antiga Santa Casa e da antiga Igreja São Francisco de Paula (PEREIRA, 2008, p.34).

Além de suas localizações privilegiadas, todos os teatros eram divididos em três volumes, onde: no primeiro volume se via os foyers, as salas de convivência, bares ou restaurantes e escadarias monumentais (quando possuíam); no segundo volume se situava as salas de espetáculos com as divisões respectivas; e, no terceiro volume, havia as áreas reservadas aos artistas e funcionários dos teatros, como o palco, os camarins, as oficinas, casa de máquinas e salas de ensaio (quando possuíam).

Sobre o aspecto de suas salas, os palcos eram do tipo "italiano" e as plateias seguiam o formato ferradura com vários andares. O número de níveis nas salas variava (em Belém do Pará, São Paulo, Rio de Janeiro, Campinas e Ribeirão Preto, eram 5 níveis - plateia, frisas, camarotes, camarotes e galeria - e em São João da Boa Vista, Santos e Jundiaí, eram 4 níveis - plateia, frisas, camarotes e galeria -), mas se via em todas elas uma hierarquização do espaço. Nesse aspecto, essas estruturas, por sua natureza hierarquizada, eram também ocupadas de forma desigual pelos públicos das cidades nas quais estavam respectivamente inseridos. Sobre esta hierarquização, Masseran (2012) afirma que

seu interior representava a composição social local. Invariavelmente, a plateia era destinada aos profissionais liberais e funcionários públicos; as frisas e camarotes, para os proprietários e autoridades, as galerias ou "poleiro" ou "galinheiro" ou gerais eram ocupadas pelos trabalhadores, imigrantes, operários” (MASSERAN, 2012, p.243).

Pelo elevado número de níveis, todos estes teatros tinham em comum uma elevada capacidade de espectadores admitidos nas suas dependências. Nos teatros das capitais (no período de suas inaugurações), do maior para o menor, vemos o de São Paulo, o do Rio de Janeiro e o de Belém do Pará, com capacidade respectiva de 1.816 lugares (BRANDÃO, 1993, p.25), 1.739 lugares (SANTOS, 2011, p.80) e 1.100 lugares 


\section{Símbolos de riqueza e modernidade: Teatros no Pará, Rio de Janeiro e São Paulo}

(SILVEIRA, 2010, p.144). Nos teatros do interior (no período de suas inaugurações), do maior para o menor, vemos o de Jundiaí, o de Campinas, o de Ribeirão Preto, o de São João da Boa Vista e o de Santos, com capacidade respectiva de 2.920 lugares (MARTINS ET AL, 1996, p.14), 1.300 lugares, 1.200 lugares (CICACCIO, 1996, p.64), 1.188 lugares (JERONIMO, 2020, p.102) e 700 lugares (PEREIRA, 2008, p.41). Nota-se que tanto as salas interioranas quanto as das capitais mantinham-se tributárias às salas-modelo europeias (Ópera Garnier, de Paris, e Alla Scala, de Milão, com 6 e 7 níveis, respectivamente), onde as diferenças sociais se refletiam na ocupação de determinado assento em determinado nível da sala. Esta tradicional e excludente configuração contrastava grandemente com os avançados métodos de construção presentes nestes edifícios, que empregava alvenaria, armação em ferro, cimento e até mesmo a utilização de concreto armado para a construção. Nesse aspecto, o caso do Pedro II é bastante interessante, uma vez que "o teatro e o edifício Meira Júnior foram as primeiras construções de concreto armado do interior paulista" (LEONE, 2010, p.25). Desta forma, estes teatros hibridizavam novos tempos de métodos construtivos com clássicos estilos de acabamento, ornamentação e disposição interna dos lugares, resultando em espécimes de "peles" clássicas com "esqueletos" modernos. Este encontro de tempos num mesmo edifício é uma característica presente na maioria das construções desta época, uma vez que nelas vemos

tantôt les ossatures de métal adoptent des formes issues de l'antiquité, de la Renaissance ou de l'age classique. Tantôt, les nouveaux matériaux de remplissage en terre émaillée ou vernisée, mis au point par industrie, utilisent des motifs empruntés à des cultures lointanes ou des styles passés. Tantôt enfin, les ossatures aériennes des nefs d'exposition sont dissimulées par de lourdes façades de maçonnerie. (CHOAY, 1983, p.222)

Esses espaços para os públicos paulistano, carioca, belenense, jundiaiense, ribeirão-pretano, campineiro, santista ou sanjoanense se comportavam, portanto, como laços com a Europa, partes de um mosaico cosmopolita, de um universo que conectava cidades do interior com capitais nacionais e com capitais mundiais. Estas conexões podem ser vistas nos métodos modernos de construção, na disposição das salas, nos materiais importados, mas, mais precisamente, no estilo interno e externo destes teatros.

Em relação ao aspecto interior das salas de espetáculos propriamente dito, podemos dividi-lo em dois grupos: do primeiro grupo fazem parte os teatros paulistano, carioca e belenense, onde as influências do barroco e do neoclássico são muito expressivas; e do segundo grupo fazem parte os teatros sanjoanense, santista, campineiro, ribeirão-pretano e jundiaiense, que se dividem em influências do Art Déco, do Art Nouveau e, também, do barroco e do neoclássico, sendo o teatro santista mais identificado com esse último estilo.

No primeiro grupo, inegavelmente, o luxo se faz muito mais presente, com a profusa utilização de douramentos, madeiras nobres, tecidos, bronzes, cristais, mármores, pinturas e pano-de-boca imensos (os últimos geralmente assinados por artistas famosos do período), muito bem trabalhados e com alegorias que representam a grandeza do município/região/estado/país - são espaços que lembram uma hibridação entre a Ópera Garnier e o Alla Scala, os dois maiores paradigmas do período. Já no segundo grupo, vemos menos luxo 


\section{Símbolos de riqueza e modernidade: Teatros no Pará, Rio de Janeiro e São Paulo}

empregado (conforme as possibilidades locais e os interesses de exploração do espaço, como o público-alvo, a participação de grandes empresários, etc.), com salas menos ornamentadas, tais como a que serviram ao público santista, com influências do neoclássico, ou ao público campineiro, com influências do Art Déco, do neoclássico e do barroco, ou aos públicos ribeirão-pretano e jundiaiense, com influências do Art Déco, ou ao público sanjoanense, com influências do Art Nouveau. Mesmo possuindo diferentes quantidades de ornamentação, todos estes espaços apresentavam as últimas tendências decorativas europeias dos períodos em que foram construídos.

Assim, nas fachadas, em todos os casos, vemos ecléticas ornamentações, por vezes mais e outras vezes menos relacionadas com os estilos barroco, neoclássico, Art Déco ou Art Nouveau, a depender também do período de construção do edifício e do vulto de seus respectivos orçamentos. Presentes em todos estão as colunas (completas ou meia-colunas, principalmente em estilo coríntio e compósito), platibandas e arremates em cima de portas e janelas. Pelas características externas dos edifícios dos dois grupos, podemos apontar afinidades maiores com os modelos inspiradores: os teatros belenense, santista, sanjoanense, campineiro e jundiaiense são mais sóbrios e "sólidos", de formato retangular, tais como o Alla Scala; já os teatros paulistano, carioca e ribeirão-pretano são mais ostensivos, com cúpulas e telhados curvos, de formato mais quadrado (levando-se em consideração seus altos telhados abobadados), tais como a Ópera Garnier. Todos eles guardam a riqueza do detalhe, a elegância dos ornatos próprios do período e a eloquência de uma sociedade que se quer fazer civilizada, muito embora a quantidade de elementos, seu apuro técnico e materiais sejam maiores e melhores naqueles com mais recursos disponíveis para a construção.

Dessa forma, concluindo estes apontamentos sobre os estilos das casas de espetáculos, podemos perceber que não apenas as fachadas, mas também as decorações internas respeitavam uma ideia de importação dos estilos em voga na Europa. Ainda assim, há diferenças. Nas localidades mais ricas, como São Paulo, Rio de Janeiro, Belém do Pará, Campinas, Santos e Ribeirão Preto, os arquitetos não pouparam recursos para complementarem a decoração das salas, enquanto que nas localidades menos ricas, como Jundiaí e São João da Boa Vista, o interior podia até mesmo ser considerado "espartano" em comparação às suas fachadas. Neste aspecto, vemos que, muito embora nas fachadas estejam presentes elementos universais (cítaras, folhas de acanto, portas de folha dupla, esculturas/alto relevos, etc.), é dentro dos teatros que a sua época é mais bem definida, com marcante decoração nos estilos em voga próprios dos períodos em que foram erguidos (exemplo do caso sanjoanense, de 1914, com fortes elementos do Art Nouveau, e nos casos jundiaiense (após reforma), campineiro e ribeirão-pretano, de 1927, 1930 e 1930, respectivamente, já com presença do Art Déco nas ornamentações).

Relacionado aos luxos internos e externos destes teatros está o emprego de altas somas para suas construções e que, a despeito das diferenças entre os contextos regionais em que se encontram, correspondiam a verdadeiros esforços financeiros da parte de seus idealizadores. Neste aspecto, apenas a bibliografia referente aos casos sanjoanense, belenense, paulistano e carioca oferecem subsídios para a discussão. 


\section{Símbolos de riqueza e modernidade: Teatros no Pará, Rio de Janeiro e São Paulo}

No caso do Theatro Municipal de São João da Boa Vista, o custo inicial do edifício foi orçado em fevereiro de 1913 em 80 contos de réis, sendo a quantia reajustada para 100 contos de réis pouco tempo depois, sendo realizadas duas chamadas de capital de 90 contos de réis e depois de mais 100 contos de réis. Desta forma, com o capital inicial mais os aditamentos e o empréstimo, o valor da construção totalizava 290 contos de réis (JERONIMO, 2020, p.96). Acompanhando a trajetória dos vultuosos aditamentos vistos no caso sanjoanense, temos os do Teatro da Paz, o Theatro Municipal de São Paulo e o Theatro Municipal do Rio de Janeiro.

O Teatro da Paz teve uma evolução de custo bastante semelhante ao seu equivalente sanjoanense. A Lei n ${ }^{\circ} 426$, de 26 de novembro de 1863 determinava a construção de uma casa de espetáculos no valor de 150 contos de réis (SILVEIRA, 2010, p.80), alterado para 300 contos de réis pela Lei ${ }^{\circ} 461$, de 25 de outubro de 1864 (SIL VEIRA, 2010, p.80). O orçamento da obra, após os estudos, foi elevado em cerca de 465 contos de réis (SILVEIRA, 2010, p.82) e, ao final da obra, custaria mais de 765 contos de réis (SILVEIRA, 2010, p.111). No caso paulistano, o custo inicial previsto era de 2.308 contos de réis, resultando em um custo final de 4.500 contos de réis, "incluindo a esplanada e anexos, quando, para colocar de pé um sobrado, gastava-se perto de setenta contos" (MACEDO, 2011, p.27). Porém, o mais espantoso de todos os orçamentos, seja por seu vulto, seja pela transposição das estimativas iniciais, é o do teatro carioca. Os projetos apresentados na concorrência aberta pela municipalidade previam que "a execução da obra não excederia o valor de 1.500:000\$000, excluindo-se, contudo, as despesas de decoração interna" (ERMAKOFF, 2010, p.49). No final das contas, o edifício custaria

(...) 10.856:000\$000, dos quais 3.344:000\$000 se destinaram ao pagamento de pessoal. Dos 7.512:000\$000 consumidos com materiais, as maiores parcelas foram devidas à decoração e ao mobiliário, que custou 1.127:000\$000, mármores e bronzes montaram a 979:000\$000 e maquinismos e rede elétrica, a 971:000\$000 (ERMAKOFF, 2010, p.66).

Se tomarmos apenas os custos da parte elétrica do teatro carioca, a de menor monta da somatória, construiríamos pouco mais de três teatros sanjoanenses. No que se refere às apreensões dos cronistas sobre o emprego delirante de capital num único edifício, as opiniões divergem. Neste sentido, Santos (2011) traz interessante consideração:

Em Buenos Aires, o projeto do Teatro Colón (...) [no] seu aspecto exterior, mais severo, é italianizado, embora o interior deva algo à Ópera de Paris. Já seu equivalente brasileiro, tanto pela sua linguagem como pela sua concepção geral, apresenta uma dívida mais direta para com os princípios defendidos por Charles Garnier. Oliveira Passos, já no memorial que acompanhava sua planta, adiantava: "Sugere a simples leitura do edital de que seja a intenção da Prefeitura de dotar a capital da República tanto de um teatro modelo como de um edifício digno de ser apresentado como monumento estético". A declaração de princípios já sugeria o futuro "delírio de mármore, de ouro, bronze e cristal", que deixaria maravilhado o cronista Luís Edmundo e indignados críticos como Lima Barreto, que anos mais tarde se referiria ao teatro como "aquele estafermo do começo da avenida, cujas colunas douradas dão-lhe grandes semelhanças com os coches fúnebres da primeira classe", "um teatro que custou não sei quanto mil contos, com ônix, mármores, assírios, no puro intuito de embasbacar os argentinos" (SANTOS, 2011, p.76, grifo nosso). 


\section{Símbolos de riqueza e modernidade: Teatros no Pará, Rio de Janeiro e São Paulo}

Com estes dados, podemos afirmar que os teatros sanjoanense, belenense, paulistano e carioca teriam custo final superior às estimativas iniciais em cerca de 3 vezes, 2 vezes, 2 vezes e 6,5 vezes, respectivamente. Nestes casos, não é necessário dizer que, não obstante o belo resultado de suas obras tanto no plano material quanto o sucesso da representação no plano simbólico, estes edifícios foram onerosos demais para os caixas das instituições que os caucionavam, causando muitas vezes desagrado na opinião pública e entre seus acionistas (quando possuíam), seja pelo alto custo, seja pelo pouco uso (mais claro no caso paulistano, aqui já tratado). De toda forma, mesmo com altos custos, os teatros foram entregues e serviam ao propósito que seus criadores/idealizadores almejaram, ou seja, inseriram suas cidades, sua região, seu estado, enfim, seu país, no contexto da modernidade. Esta inserção é bem ilustrada por Santos (2011), que demonstra que para

o cronista ["B.T.", da revista Fon Fon] e outros paladinos do espírito da belle-époque, o novo teatro era antes de mais nada o novo símbolo da nova metrópole que queria dar as costas definitivamente ao seu passado de cidade colonial, com sua arquitetura bisonha, suas ruas estreitas e vielas sinuosas. "Na deslumbrante sala do Theatro Municipal, com a Réjane a viver as últimas criações da alta comédia, num ambiente de mármore, de oiro, as casacas impecáveis a roçar as sedas caras, trabalhadas chez Pascin e depois o chocolate no restaurante Assírio - que nenhum teatro do mundo possui - e o desfile dos autos pelas ruas asfaltadas e floridas fulgindo de luz elétrica, aí sim pode se ter uma impressão real e sólida da moderna elegância, irmã do conforto e do luxo. Tudo o mais são histórias", sentenciou, dando por encerrada a discussão. (SANTOS, 2011, p.86, grifo nosso) ${ }^{8}$.

\section{AS DIFERENÇAS INTRAGRUPOS: FINANCIAMENTO DE SUAS CONSTRUÇÕES, UTILIZAÇÃO DE ÁREAS INTERNAS E CONTEXTO ECONÔMICO DAS CONSTRUÇÕES}

Por fim, devemos fazer uma ressalva. Coligar os teatros em grupos não significa considerá-los praticamente iguais. Vemos, portanto, diferenças intragrupos que não devem passar despercebidas. Uma delas é a questão do financiamento dos edifícios do segundo grupo: os teatros Pedro II e Polytheama foram financiados por empresas particulares (o primeiro, pela Companhia Cervejaria Paulista, e o segundo, pelo cidadão Albano Pereira); o Municipal Carlos Gomes (da mesma forma que o Municipal de São Paulo, Municipal do Rio de Janeiro e Teatro da Paz) foi erguido sob os auspícios do poder público; o Theatro Guarany foi construído por uma sociedade cotizada por diversos indivíduos através de uma empresa criada para esse fim, chamada Associação do Theatro Guarany; por fim, o Municipal de São João da Boa Vista foi construído a partir da união do poder público sanjoanense com um grupo de acionistas que formaram a Companhia Theatral Sanjoanense.

\footnotetext{
${ }^{8}$ Esta noção de assombro e de orgulho também está presente no caso paulistano, onde Brandão (1993) afirma que "com a inauguração do Theatro Municipal e o notável congestionamento, o primeiro de grande porte na história da cidade, São Paulo penetrava na modernidade. 12 de setembro de 1911. O cronista de A Vida Moderna, revista ilustrada popular e de atualidades, registrou: 'Não parece que estamos em São Paulo - comentou uma senhora graciosa'. Esta tinha sido uma das intenções, quando se pensou na necessidade de a cidade ter um teatro à altura da Ópera de Paris, do Scala de Milão, ou qualquer outra sala célebre do mundo. Aquela noite histórica de 12 de setembro de 1911 tinha sido pensada muito antes. Há dezesseis anos se esperava por ela" (BRANDÃO, 1993, p.17).
} 


\section{Símbolos de riqueza e modernidade: Teatros no Pará, Rio de Janeiro e São Paulo}

Uma outra diferença intragrupo é sobre a utilização, para além da sala de espetáculos, das demais áreas internas. Se é verdade que os teatros paulistano, carioca, belenense, ribeirão-pretano e campineiro consistiam em completos locais de sociabilidade, oferecendo espaços luxuosos em que funcionavam bares e restaurantes ou mesmo espaços de convívio, como os salões para conversas entre espetáculos, não vemos o mesmo no caso sanjoanense, santista ou jundiaiense. No caso sanjoanense, não está clara a utilização massiva dos outros espaços do teatro para uma sociabilização tanto quanto dos outros exemplos, a não ser pela utilização do bar no segundo andar no período de espetáculos e de uma outra sala para a realização de conferências. No caso de Jundiaí ou Santos, não está claro se havia o uso de outros espaços dentro daqueles teatros que não fossem suas salas de espetáculos.

Ainda no segundo grupo, vemos uma última diferença marcante. Enquanto o teatro sanjoanense assim como os teatros de Santos, São Paulo, Rio de Janeiro, Jundiaí e o de Belém do Pará foram inaugurados no zênite de suas economias agroexportadoras, os teatros campineiro e ribeirão-pretano foram inaugurados no ocaso delas. Isso significa também que a maioria dos teatros aqui analisados foram erigidos no auge do ideário das elites europeizadas, que prometiam um radioso futuro de prosperidade e modernidade, enquanto que outros teatros, ainda que carregando em sua materialidade a evocação daqueles ideais e prosperidade, representavam o fim daquela outrora pujante economia agroexportadora. Exemplos dessa atribulada época foram os cortes realizados no orçamento de acabamento do teatro Pedro II, "como a substituição de mármores por granilite e redução de sua capacidade, de 2.500 lugares para 1.200" (CICCACIO, 1996, p.64), e a sua simples inauguração, com exibição filmes:

A situação política e econômica era tão grave que nenhuma companhia de ópera aceitou convite para inaugurar o teatro. Mas nada abateu seus mentores, embora o evento inaugural tenha sido extremamente simples. Começou com um rápido discurso de João Meira Júnior, entregando o espaço ao público. Seguiram-se a execução do Hino Nacional Brasileiro e a protofonia da ópera $O$ Guarani, de Carlos Gomes, pela sinfônica precursora da atual Sinfônica de Ribeirão Preto (...) Encerrou com a exibição do filme Alvorada de Amor, da Paramount, com Maurice Chevallier e Jannete MacDonald (CICCACIO, 1996, p.66/67).

\section{CONSIDERAÇÕES FINAIS}

Podemos considerar que, independentemente do período e do lugar que ostenta esse moderno melhoramento urbano, aqueles imensos edifícios teatrais possuíam facetas irresistíveis de simbolismo. Caros, de elaborados projetos, com desafios técnicos muito além do que poderíamos supor, exigindo trabalhadores qualificados e materiais vindos do exterior, aquelas construções eram parte de discursos eloquentes de desenvolvimento e riqueza, além de simbolizarem cristalizados poderios (seja de oligarcas, clãs, grupos políticos, classes sociais ou cidades) dentro de suas regiões específicas ou a nível nacional: o Teatro da Paz, na Amazônia; o Theatro Municipal de São Paulo, no estado mais próspero da nação; o Theatro Municipal do Rio de Janeiro, no país inteiro; o Polytheama, na região da Paulista; o Guarany, no Litoral; o Theatro Carlos 


\section{Símbolos de riqueza e modernidade: Teatros no Pará, Rio de Janeiro e São Paulo}

Gomes, na Baixa Mogiana; o Theatro Municipal de São João da Boa Vista, na Média Mogiana; e, por fim, o Theatro Pedro II, na Alta Mogiana.

Assim, seja na vastidão da Amazônia, nas localidades paulistas enriquecidas pelo café, na nascente metrópole ou na capital federal, estes teatros significaram muitíssimo mais do que apenas lugares de diversão, lucro e privilegiada vitrine social. Eles são retratos de uma época, testemunhas privilegiadas do momento em que o país se desejava fazer moderno e era inundado de tecnologias, imigrantes, ideais e divisas provenientes de uma economia fortemente pautada pela exportação de gêneros primários.

Esse pequeno estudo não se conclui, visto que outras semelhanças e diferenças podem ser encontradas por olhares mais atentos. O que se pretendeu foi deixar claro que, mesmo sendo construções ímpares em suas cidades e regiões, estes teatros estavam conectados e relacionados entre si, ao atenderem um desejo comum de inserção na modernidade e no cosmopolitismo que transcendeu seus tempos e lugares (abrangendo construções do último quartel do século XIX aos anos 1930, na Amazônia ou na Mogiana). Essa relação entre teatros de diferentes lugares e épocas, construídos no desejo de "libertação" do passado "incivilizado" e de comunhão com as culturas europeias (ambições características de fins do século XIX e início do século XX), portanto, não é nada surpreendente naquelas sociedades que possuíam os mesmos modelos, as mesmas inspirações e os mesmos ideais, colocados em prática por elites que se consideravam cosmopolitas, mesmo que de fachada.

\section{REFERÊNCIAS BIBLIOGRÁFICAS}

AMARAL, Antônio Barreto do. História dos velhos teatros de São Paulo. São Paulo: Imprensa Oficial, 2006, 688p.

BRANDÃO, Ignácio de Loyola. Teatro Municipal de São Paulo - Grandes Momentos. São Paulo: DBA Artes Gráficas; Gráfica Círculo, 1993, 119p.

CHOAY, Françoise. Pensées sur la ville, arts de la ville. In: AGULHON, Maurice (Org.). Histoire de la France Urbaine. Paris: Éditions du Seuil, vol. 4, 1983, 672p.

CICCACIO, Ana Maria. Theatro Pedro II - Espaço Reconquistado. Ribeirão Preto: São Francisco Gráfica e Editora Ltda., 1996, 142p.

ERMAKOFF, George. Theatro Municipal do Rio de Janeiro 100 anos. Rio de Janeiro: G. Ermakoff Casa Editorial, 2010, 352p.

FARDIN, Sônia Aparecida (Org.). Fragmentos de uma demolição - História Oral do Theatro Municipal Carlos Gomes. Campinas: Editora Átomo, 2000, 226p.

JERONIMO, Luis Pedro Dragão. Uma memória e um espaço restaurado em dois tempos: $O$ Theatro Municipal de São João da Boa Vista no momento de sua construção (1914) e a partir de seu restauro, dos anos 1980 aos dias atuais. 2020. 716p. Dissertação (Mestrado em História Social) - Faculdade de Filosofia, Letras e Ciências Humanas. Universidade de São Paulo. 


\section{Símbolos de riqueza e modernidade: \\ Teatros no Pará, Rio de Janeiro e São Paulo}

LEONE, Matilde. Theatro Pedro II - Palco da Cultura de Ribeirão Preto. Ribeirão Preto: São Francisco Gráfica e Editora Ltda., 2010, 140p.

MACEDO, Carlos Eduardo Martins (Org.). Theatro Mvnicipal de São Paulo 100 anos - Palco e Plateia da Sociedade Paulista. São Paulo: Editora DMP, 2011, 192p.

MARTINS, Penha Maria Camunhas; FERRAZ, Marcelo Carvalho; FANUCCI, Francisco. Teatro

Polytheama de Jundiaí. Jundiaí: Hamburg, 1996, 96p.

MASSERAN, Paulo Roberto. Theatro Paulista (1840-1930) - Fundamentos da arquitetura teatral em

São Paulo. São Paulo: Editora Unesp, 2011, 266p.

MORAES, Júlio Lucchesi. São Paulo Capital Artística - A cafeicultura e as artes na belle époque (19061922). Rio de Janeiro: Beco do Azougue, 2014, 247p.

PEREIRA, Taís Assunção Curi. Theatro Guarany - o renascer de um palco centenário. Santos, SP:

Comunnicar Editora, 2008, 144p.

SANTOS, Nubia Melhem (Org.). Theatro Municipal do Rio de Janeiro - um século em cartaz * running for a century. Rio de Janeiro: Editora Juá; Editora Senac Rio, 2011, 452p.

SILVEIRA, Rose. Histórias Invisíveis do Teatro da Paz. Belém: Editora Paka-Tatu, 2010, 287p.

Texto recebido em: 06/08/2020

Texto aprovado em: 10/09/2020 